\title{
La autonomía local en el trámite de aprobación del planeamiento urbanístico general (a propósito de la Sentencia del Tribunal Superior de Justicia de Murcia, número 712/2000, de 29 de septiembre y de la Sentencia del Tribunal supremo, de 30 de octubre de 2003)
}

\author{
Teresa María Navarro Caballero \\ Departamento de Derecho Administrativo de la Universidad de Murcia
}

Sumario: I. PLANTEAMIENTO. II. LA SENTENCIA NÚM. 712/2000, DE 29 DE SEPTIEMBRE, DEL TRIBUNAL SUPERIOR DE JUSTICIA DE MURCIA. 1. Alcance de la modificación del planeamiento efectuada. 1.1. Existencia de una alteración sustancial del planeamiento. 1.2. La importancia del trámite de información pública como cauce de la esencial participación ciudadana en el ámbito medioambiental. 2. La necesidad de evaluación de impacto ambiental. III. LA SENTENCIA DEL TRIBUNAL SUPREMO DE 30 DE OCTUBRE DE 2003. LA INELUDIBLE EXIGENCIA DE LA PREVIA EVALUACIÓN DE IMPACTO AMBIENTAL. IV. EL PRINCIPIO DE AUTONOMÍA LOCAL COMO LÍMITE DEL CONTROL AUTONÓMICO EN LA APROBACIÓN DEL PLANEAMIENTO URBANÍSTICO. 1. Improcedente aprobación definitiva del planeamiento por parte de la Comunidad Autónoma de la Región de Murcia. Necesidad de un nuevo pronunciamiento municipal. 2. Necesaria reinterpretación del concepto de «interés local» para completar el principio de autonomía local. 2.1. Exigencia de reconocer al Municipio la facultad de aprobar definitivamente el planeamiento general para alcanzar la plenitud del principio de autonomía local en materia urbanística. 2.2. Fórmulas que garantizan la ineludible protección de los intereses supralocales. 2.2.1. El carácter condicionado de los planes urbanísticos. 2.2.2. Emisión de informes preceptivos y, en su caso, vinculantes por parte de la Administración titular del interés afectado. 2.2.3. La coordinación como técnica rectora de las relaciones interadministrativas. 2.2.4. El control jurisdiccional del planeamiento urbanístico general. V. CONCLUSIÓN

\section{PLANTEAMIENTO}

La autonomía local, como poder derivado que es, ha de ceñirse en su primera determinación a los estrictos límites que la Constitución le configura. Ciertamente, ésta le reconoce el poder de gestionar sus propios intereses pero sin concretar cuáles sean los mismos, pues remite su determinación a la ley, ya estatal ya autonómica. Así pues, son ambos legisladores los encargados de delimitar lo que debe entenderse por interés local, de 
donde se desprende el «carácter bifronte» del régimen local. Dado el riesgo que para la existencia misma de los entes locales representa tal opción constitucional, el Alto Tribunal español ha importado la idea germana de la «garantía institucional». Como es sabido, ésta tiende a proteger aquellas instituciones, cual es la municipal, que se consideran componente esencial de la organización jurídico-política y cuya preservación se juzga, por ello, indispensable para asegurar los principios constitucionales. La garantía institucional no asegura, sin embargo, un contenido concreto o un ámbito competencial determinado, sino la preservación de la institución en términos reconocibles para la imagen que de la misma tiene la conciencia social en cada tiempo y lugar, el legislador no puede limitarla de tal modo que se le prive de sus posibilidades de existencia real como institución, para convertirla solamente en un nombre vacío de contenido. Dicho de otro modo, es el núcleo esencial de la institución lo que la Constitución garantiza.

Ahora bien, lo anterior resulta, sin embargo, insuficiente para las vulneraciones puntuales o concretas que el legislador pueda efectuar sobre la autonomía local, esto es, lo que en Alemania ha venido a denominarse «el silencioso vaciamiento de la autonomía local». En el presente trabajo, a propósito del comentario de dos pronunciamientos jurisprudenciales - la sentencia del Tribunal Superior de Justicia de Murcia, de 29 de septiembre de 2000 y la sentencia en casación del Tribunal Supremo de 30 de octubre de 2003 - se reflexiona sobre la anterior afirmación. Dichas sentencias, principalmente la primera, dan pie a un importante debate sobre dos cuestiones de suma trascendencia: de un lado, la inadmisible anulación o, más bien, sustitución de la voluntad de los entes locales por la de otra Administración territorial, en detrimento del principio de autonomía local y, del otro, la imposibilidad de eludir el trámite esencial de la previa evaluación de impacto ambiental en el procedimiento autorizatorio de una determinada actividad, cuando ésta encaja en los supuestos legalmente establecidos al efecto. Siendo esta última cuestión menos controvertida, nuestro estudio profundizará en el principio de autonomía local y en la pretendida reinterpretación del concepto de «interés local» como modo de completar el mismo. Previamente efectuaremos una sucinta exposición y comentario de los fundamentos de hecho y de derecho de las sentencias citadas. 


\section{LA SENTENCIA NÚM. 712/2000, DE 29 DE SEPTIEMBRE, DEL TRIBUNAL SUPERIOR DE JUSTICIA DE MURCIA}

La Sentencia número 712/2000, de la Sección $1^{a}$ de la Sala de lo Contencioso del Tribunal Superior de Justicia de Murcia, de 29 de septiembre (Ponente Sr. López Pellicer), resuelve el recurso contencioso-administrativo número 437/1997 interpuesto por la Asociación de Naturalistas del Sureste («ANSE»). Dicho recurso pretende la declaración de nulidad de la Orden de la Consejería de Política Territorial y Obras Públicas, de la Comunidad Autónoma de la Región de Murcia, de 30 de julio de 1996, así como del Acuerdo del Consejo de Gobierno autonómico de 24 de enero de 1997, que desestima los recursos administrativos interpuestos frente a la citada Orden ${ }^{1}$. Fueron parte demandada en el recurso la Administración autonómica - concretamente, la Consejería de Política Territorial y Obras Públicas - y parte codemandada el Ayuntamiento de Cartagena y la Inmobiliaria Altonia, SL, que había promovido la modificación del planeamiento urbanístico.

El objeto de la Orden de la Consejería de Política Territorial y Obras Públicas impugnada es la aprobación definitiva de la modificación número 55 del Plan General de Ordenación Urbana de Cartagena, en «Lo Poyo», que reclasifica la totalidad de los terrenos situados en su ámbito como suelo urbanizable no programado. La Sentencia 721/2000 estima el recurso en su totalidad y ordena la anulación de los actos administrativos impugnados por no ser conformes a Derecho. A la vista de las alegaciones de las partes el fallo se asienta en dos consideraciones básicas que, en un breve análisis, se exponen por separado.

\section{Alcance de la modificación del planeamiento efectuada}

\subsection{Existencia de una alteración sustancial del planeamiento}

La sentencia del Tribunal Superior de Justicia de Murcia considera la modificación número 55 del Plan General de Ordenación Urbana de Car-

\footnotetext{
${ }^{1}$ Es conveniente aclarar que la fecha de la Orden de la Consejería de Política Territorial y Obras Públicas - 2 de agosto de 1996- que figura en la Sentencia del Tribunal Superior de Justicia de Murcia y, por ende, en la Sentencia del Tribunal Supremo es inexacta. Dicha Orden es de 30 de julio de 1996 y se publicó en el Boletín Oficial de la Región de Murcia el 14 de agosto del mismo año.
} 
tagena como una alteración sustancial del planeamiento. En este sentido, afirma que en ningún caso puede ser considerada dicha modificación como una alteración o cambio aislado del planeamiento, de un lado, por su extenso ámbito superficial —concretamente 469 hectáreas- y, del otro, porque tal modificación afecta a un Paisaje Protegido: el Saladar de Lo Poyo $^{2}$. Se trata de una modificación que atañe a un elemento esencial del suelo objeto de reclasificación y que cabe considerar, por ello, como una alteración sustancial ${ }^{3}$. Consecuentemente, el carácter esencial de la mutación del planeamiento, en razón de su específica funcionalidad y trascendencia, es capaz de generar no sólo un nuevo pronunciamiento municipal sino también y previamente a ello, una nueva información pública, conforme a lo que establece la Ley del Suelo (artículo 49.1 del Texto Refundido de la Ley del Suelo, de 9 de abril de 1976) y su Reglamento de Planeamiento (artículo 161.1) ${ }^{4}$.

Conviene adelantar que la exigencia de un nuevo pronunciamiento municipal para reclasificar el suelo urbanizable no programado es consecuencia de que, en el supuesto de hecho es la Administración autonómica la que unilateralmente acuerda la nueva clasificación del suelo incluido en la modificación número 55 del Plan General de Ordenación Urbana, transformando la clasificación de urbanizable programado, acordada inicial y provisionalmente por la Administración actuante - el Ayuntamiento de Cartagena-, en urbanizable no programado. Tal actuación es justificada por la Administración autonómica en virtud de la ausencia de la programación detallada requerida por el suelo urbanizable programado. Sin embargo, como se expondrá más adelante, el principio de autonomía local puede representar un límite a iniciativas de este tipo.

\footnotetext{
${ }^{2}$ La calificación del Saladar de Lo Poyo como Paisaje protegido se efectúa en la Disposición Adicional Tercera, Dos, 3, de la Ley 4/1992, de Ordenación y Protección del Territorio de la Región de Murcia, que - de conformidad con el artículo 21.1 de la Ley estatal 4/1989, de la Conservación de Espacios Naturales y de la Flora y la Fauna Silvestres_- declara «paisaje» a los Espacios abiertos e Islas del Mar Menor, dentro de los límites trazados en el Anexo $C$ de la misma.

${ }^{3}$ Fundamento de Derecho Segundo 1 de la Sentencia 721/2000, del Tribunal Superior de Justicia de Murcia (RJCA 20011240).

${ }^{4}$ Los artículos 49.1 del TRLS de 1976 y 161.1 del Reglamento de Planeamiento establecen, con el mismo tenor, que «las modificaciones de cualquiera de los elementos de los Planes se sujetarán a las mimas disposiciones enunciadas para su formación».
} 


\subsection{La importancia del trámite de información pública como cauce de la esencial participación ciudadana en el ámbito medioambiental}

Por lo que se refiere al trámite previo de información pública, la sentencia de instancia señala que, en riguroso cumplimiento del principio de contrarius actus, que impone la observancia de los mismos trámites que hubieron de seguirse por la Administración local para el ejercicio de la potestad variandi, la decisión de variar la calificación de la categoría del suelo, en razón de constituir un cambio esencial, hubo de haberse sometido a información pública, previamente a la nueva aprobación provisional local y definitiva autonómica ${ }^{5}$. La exigencia y la trascendencia de este trámite procedimental es indiscutible para el Tribunal de instancia debido a la discrecionalidad con que la Administración actúa respecto del suelo urbanizable. El riguroso cumplimiento de la información pública por parte de las Administraciones implicadas permitirá a los ciudadanos influir en la toma de decisiones administrativas en un sector que se encuentra poco predeterminado legalmente: el de la ordenación urbanística general.

En efecto, la responsabilidad directa de los ciudadanos en la conservación del medio ambiente se encuentra constitucionalmente determinada en el artículo $45 \mathrm{CE}$, que configura el derecho de la comunidad en su conjunto a un medio ambiente adecuado, reservando su realización no sólo a los poderes públicos sino también a todos los miembros de aquella ${ }^{6}$. De hecho, el medio ambiente se consagra en la Constitución como un principio rector del ordenamiento, no como un derecho fundamental invocable por la vía amparo. Por ello cualquier interpretación que se realice de su

\footnotetext{
${ }^{5}$ Fundamento Jurídico Segundo 1 de la Sentencia 712/2000, del TSJM.

${ }^{6}$ Dice expresamente el artículo constitucional que «1. Todos tienen el derecho a disfrutar de un medio ambiente adecuado para el desarrollo de la persona, así como el deber de conservarlo. 2. Los poderes públicos velarán por la utilización racional de todos los recursos naturales, con el fin de proteger y mejorar la calidad de vida y defender y restaurar el medio ambiente, apoyándose en la indisponible solidaridad colectiva. 3. Para quienes violen lo dispuesto en el apartado anterior, en los términos que la ley fije se establecerán sanciones penales o, en su caso, administrativas, así como la obligación de reparar el daño causado». Sin embargo, la doctrina no es unánime a la hora de depurar la naturaleza jurídica del derecho al medio ambiente; sin duda resultan llamativas aquellas posturas que, en función de la creciente sensibilidad sobre el medio ambiente, incluyen aquel entre los derechos fundamentales de las personas, como un derecho de «tercera generación o de solidaridad», al igual que el derecho a la paz o al desarrollo (Alli Aranguren, J. C., «Dos sentencias sobre las competencias y la naturaleza jurídica de la declaración de impacto ambiental», Actualidad Administrativa, núm. 35, 2001, p. 1198). Una completa exposición del debate doctrinal que se cierne sobre la naturaleza jurídica del derecho al medio ambiente como derecho fundamental o como derecho subjetivo puede verse en Betancor Rodríguez, A., Instituciones de Derecho Ambiental, La Ley, Madrid, 2001, pp. 375 y siguientes.
} 
régimen jurídico ha de efectuarse desde la perspectiva del artículo 45 de nuestra Norma Fundamental y del valor que el artículo 53.3 CE otorga a los principios rectores de la política social y económica; en el buen entendimiento de que «los preceptos contenidos en el capítulo tercero del Título I de la Constitución, pese a dar bajo la rúbrica de "principios rectores de la política social y económica" no constituyen meras normas programáticas que limiten su eficacia al campo de la retórica política o de la inútil semántica propia de las afirmaciones demagógicas» ${ }^{7}$.

Así pues, de la invocada responsabilidad directa de los ciudadanos en la conservación del medio ambiente se deriva no sólo la obligación de una conducta cívica comprometida con la conservación del entorno sino también la necesidad de arbitrar cauces adecuados que permitan a todos los ciudadanos participar activamente en su protección. En este sentido, la defensa del medio ambiente - en cuanto bien jurídico colectivo- se configura hoy como uno de los ámbitos en los que se produce una manifestación intensa del principio de participación ciudadana, propio de las democracias pluralistas modernas ${ }^{8}$. Sin lugar a dudas, los Convenios internacionales han jugado un intenso papel a este respecto. Representa buena prueba de ello el Principio 10 de la Declaración de la Conferencia de las Naciones Unidas sobre Medio Ambiente y Desarrollo, celebrada en Río de Janeiro en junio de 1992, a cuyo tenor

«El mejor modo de tratar las cuestiones ambientales es con la participación de todos los ciudadanos interesados, en el nivel que corresponda. En el plano nacional, toda persona deberá tener acceso adecuado a la información sobre el medio ambiente de que dispongan las autoridades públicas, incluida la información sobre los materiales y las actividades que ofrecen peligro en sus comunidades, así como la oportunidad de participar en los procesos de adopción de decisiones. Los Estados deberán facilitar y fomentar la sensibilización y la participación del público poniendo la información a disposición de todos. Deberá proporcionarse acceso efectivo a los procedimientos judiciales y administrativos, entre éstos el resarcimiento de daños y los recursos pertinentes».

En el desarrollo de los instrumentos de participación tiene un papel destacado el Convenio de la Comisión Económica de las Naciones Unidas para Europa sobre «El acceso a la información, la participación del público en la toma de decisiones y el acceso a la justicia en asuntos medioambientales», adoptado en la Conferencia Ministerial «Medio Ambiente para Europa» celebrada en Aarhus, Dinamarca, el 25 de junio de 1998 y que

\footnotetext{
${ }^{7}$ STS de 25 de abril de 1989, Fundamento de Derecho Tercero (RJ 1989\3233).

${ }^{8}$ Lozano Cutanda, B., Derecho Ambiental Administrativo, $4^{\text {a }}$ edición, Dykinson, Madrid, 2003, p. 126.
} 
entró en vigor, para los Estados que lo han ratificado - entre ellos todos los Estados miembros de la Unión Europea-, el 30 de octubre de 2001. El artículo 1 del citado Convenio dispone que

«A fin de contribuir a proteger el derecho de cada persona, de las generaciones presentes y futuras, a vivir en un medio ambiente que permita garantizar su salud y su bienestar, cada Parte garantizará los derechos de acceso a la información sobre el medio ambiente, la participación del público en la toma de decisiones y el acceso a la justicia en materia medioambiental de conformidad con las disposiciones del presente Convenio».

No podemos ignorar que, como sucede en el caso de autos, la participación ciudadana en el ámbito medioambiental cuenta con unos protagonistas singulares que hacen de aquella uno de sus principales cometidos: las organizaciones no gubernamentales con fines ambientales. En efecto, el papel de las organizaciones ecologistas es determinante en la toma de conciencia generalizada sobre los problemas ambientales así como en la potenciación de los instrumentos jurídicos de control y tutela. De este modo, tales organizaciones ambientales —además de colaborar con los poderes públicos para asegurar una efectiva aplicación de las normas y medidas de tutela ambiental - actúan como un elemento de control de la Administración, al ejercer el derecho de participación. Así ocurre en el supuesto de hecho de la sentencia comentada en la que es, precisamente, una organización ecologista - la Asociación de Naturalistas del Surestela que interpone el recurso que origina la declaración de nulidad del acto agresor del medio ambiente ${ }^{9}$.

\footnotetext{
${ }^{9}$ Es patente, pues, la importante y cualificada labor que este tipo de asociaciones realizan, dado su elevado nivel de compromiso con la protección y defensa del medio ambiente así como el eminente grado de eficiencia que, generalmente, conlleva su actuación. Resulta buena prueba del destacado papel de las organizaciones no gubernamentales de ámbito ecologista el que el nacimiento y madurez del Derecho ambiental norteamericano se deba en gran parte a éstas. De este modo, la mayoría de los contenciosos de aquel país llevan el nombre de una asociación ecologista: Wilderness Society vs. Hickel, Sierra Club vs. Ruckelshaus, Natural Wildlife federation vs. Gorsuch, etc. (Lozano Cutanda, B., Derecho Ambiental Administrativo, ob. cit., p. 128). De los muchos ejemplos que podríamos encontrar en nuestro país podemos recordar el destacado papel desempeñado por grupos ecologistas en la denuncia de la disposición adicional $8^{\text {a }}$ de la Ley $1 / 2001$, de Régimen del Suelo de la Región de Murcia. Tal disposición encubre la desprotección de buena parte del Litoral Sur de la Región de Murcia al remitir «el ajuste» de los límites de los Espacios Naturales Protegidos regionales a los límites de los Lugares de Importancia Comunitaria fijados en un Acuerdo del Consejo de Gobierno de 28 de julio de 2000, entre los que no existe correspondencia ya que se limita a incluir un listado de nombres de lugares, junto a un código de identificación, sin incluir ninguna referencia a la superficie o correspondencia con los Espacios Naturales Protegidos de la Región de Murcia. La actuación incesante y desde diversos frentes de las organizaciones ecologistas - principalmente de Ecologistas en Acción-culminó en la interposición del recurso de inconstitucionalidad número 4288-2001 contra la citada disposición adicional.
} 
Por su parte, la doctrina jurisprudencial también es clara en cuanto a la necesidad de un nuevo trámite de información pública y viene manteniendo que éste «únicamente es exigible cuando las alteraciones sean de una importancia tal que lleven aparejada la sustitución de las normas objeto de las prescripciones por otras distintas». Es decir, sólo aquellas modificaciones que desnaturalicen el plan de una manera importante o esencial, al afectar a las líneas o criterios básicos del mismo, determinan la existencia del carácter sustancial ${ }^{10}$. De este modo, «el concepto jurídico indeterminado de "modificaciones sustanciales" en el planeamiento —además de no presumirse, como señala la STS de 11 de julio de 1987— ha de ser interpretado restrictivamente por economía procedimental, puesto que la calificación legal de modificación "sustancial", que requiere la repetición del trámite de información pública en garantía de los administrados, exige que las rectificaciones o cambios introducidos en el trámite de aprobación definitiva, respecto de los que contuviese el proyecto de planeamiento aprobado provisionalmente, han de ser tan cualificados que merezcan el calificativo de "sustanciales"». Ello «solamente sucede cuando (los cambios) impongan un nuevo esquema de planeamiento, alterando de manera importante o esencial las líneas y criterios básicos del Plan y su propia estructura, sin que sea precisa una nueva información pública cuando las modificaciones introducidas afecten solamente a aspectos o extremos concretos de aquel Plan, siempre que mantenga dicho esquema fundamental del planeamiento aprobado provisionalmente $y$, en definitiva, no quede afectado el modelo territorial dibujado en el mismo» ${ }^{11}$. En este sentido, concreta la STS de 30 de diciembre de 1985, los cambios en la normativa urbanística, zonificación, ampliación de zonas verdes y otras alteraciones puntuales no tienen carácter sustancial, si, pese a ellas, el plan mantiene las líneas básicas esenciales y criterios determinantes que lo configuran. De este modo, la información pública nueva y la audiencia a las Corporaciones sólo es necesaria cuando la alteración es de tal entidad que las modificaciones determinan una variación tan importante, que el planeamiento pasa a ser algo distinto del provisionalmente aprobado ${ }^{12}$.

Pues bien, en el supuesto de hecho de la sentencia comentada la modificación implicaba una importante alteración del modelo territorial al posibilitar la construcción de 4.400 hectáreas y 3.000 plazas hoteleras, por lo que, como acertadamente señala la sentencia de instancia, mereciendo el calificativo de sustancial exige una nueva información pública con la fina-

\footnotetext{
${ }^{10}$ SSTS de 26 de diciembre de 1991 (RJ 19921378) y de 11 de julio de 1987 (RJ 1987\6875).

${ }^{11}$ STS de 26 de diciembre de 1991, Fundamento de Derecho Segundo (RJ 19991378).

${ }^{12}$ STS de 30 de diciembre de 1985 (RJ 1985\5949).
} 
lidad de ofrecer una nueva oportunidad a la participación ciudadana, claramente reforzada en la Constitución española ${ }^{13}$.

\section{La necesidad de Evaluación de Impacto Ambiental}

La especial trascendencia que la tutela ambiental tiene respecto a la actuación administrativa de que se trata impone la exigencia de someter a evaluación de impacto ambiental la modificación número 55 del Plan General de Ordenación Urbana de Cartagena. En efecto, los terrenos sobre los que se habilitan nuevos desarrollos urbanísticos colindan con un área sometida a una especial protección, ya que, como se ha puesto de manifiesto, está declarada «Paisaje Natural» por la Ley 4/1992, de Ordenación y Protección del Territorio de la Región de Murcia.

La necesidad de previa evaluación de impacto ambiental de la actuación administrativa controvertida se deriva tanto de la legislación estatal básica como de la propia legislación regional ${ }^{14}$. De este modo, el artículo 1.1 del Real Decreto Legislativo 1302/1986, de 28 de junio, de Evaluación de

\footnotetext{
${ }^{13}$ Vid. artículos 9.2 y 105 a) de la Constitución española.

${ }^{14}$ El artículo 45 de la Constitución — ha dicho el Tribunal Constitucional- «recoge la preocupación ecológica surgida en las últimas décadas en amplios sectores de opinión que ha plasmado también en numerosos documentos internacionales. En su virtud no puede considerarse como objetivo primordial y excluyente la explotación al máximo de los recursos naturales, el aumento de la producción a toda costa, sino que se ha de armonizar la «utilización racional» de esos recursos con la protección de la naturaleza, todo ello para el mejor desarrollo de la persona y para asegurar una mejor calidad de la vida» (STC 64/1982, de 4 de noviembre, Fundamento Jurídico 2). Y, desde luego, qué mejor manera de proteger el medio ambiente y de prevenir los daños al mismo que conociendo previamente los efectos que sobre aquel pueden tener las actividades humanas potencialmente dañinas del entorno. De este modo podrán ser evitadas o, al menos atenuadas mediante la adopción de medidas o proyectos alternativos menos transgresores del medio. Como bien sabemos, ésa es la finalidad de la evaluación de impacto ambiental, lo que la convierte en una técnica generalizada de protección ambiental, intrínsecamente relacionada con el principio de prevención más que con el de precaución. Ahora bien, la evaluación de impacto ambiental se ha convertido en un instrumento jurídico deslucido y, en este sentido, el caso de autos representa un significativo exponente de lo que la doctrina viene largo tiempo denunciando. En efecto, la evaluación de impacto ambiental representa uno de los instrumentos jurídicos más importantes y fundamentales en materia medioambiental, pues constituye la técnica que mejor traslada la esencia del principio de prevención al ámbito jurídico en materia medioambiental. Sin embargo, y pese a su importancia, la realidad práctica y jurídica han desvirtuado su valor. A ello han contribuido varios motivos, como puede ser la existencia de tres niveles de ordenación, una regulación confusa y susceptible de diferentes interpretaciones, una jurisprudencia comunitaria tardía, una jurisprudencia nacional confundida y desconocedora de la relevancia del ordenamiento jurídico comunitario, así como una práctica administrativa lenta y, en demasiadas ocasiones, contradictoria (AGUDo GonzÁLEZ, J., «Evaluación de impacto ambiental: problemas jurídicos», Revista de Derecho Urbanístico y Medio Ambiente, núm. 176, 2000, pp. 220-221).
} 
Impacto Ambiental, establece que los proyectos, públicos o privados, consistentes en la realización de las obras, instalaciones o de cualquier otra actividad comprendida en su anexo I deberán someterse a la evaluación de impacto ambiental. Dentro del mencionado anexo I, el Grupo 9 recoge «las transformaciones de uso del suelo que impliquen eliminación de la cubierta vegetal arbustiva, cuando dichas transformaciones afecten a superficies superiores a 100 hectáreas» ${ }^{15}$.

Conviene resaltar que la inclusión de la citada actividad entre los proyectos del anexo I es determinante, en la medida en que conlleva la obligación absoluta de realizar Evaluación de Impacto Ambiental. Por el contrario, si su inclusión se hubiera verificado en el Anexo II, la obligación de evaluar previamente las consecuencias medioambientales negativas de la actividad proyectada no existiría en todo caso, sino tan sólo cuando así lo decida el órgano ambiental en cada caso ${ }^{16}$. De otro lado, el Anexo I de la Ley 1/1995, de 8 de marzo, de Protección del Medio Ambiente de la Región de Murcia, establece que han de someterse a la previa evaluación de impacto ambiental los Planes Generales Municipales de Ordenación Urbana, sus revisiones y modificaciones que reduzcan la superficie de suelo no urbanizable.

Así pues, el requerimiento legal de la previa evaluación de impacto ambiental era insoslayable, como acertadamente pone de manifiesto el Tribunal de instancia, refutando los argumentos defensivos de la parte demandada. Éstos se reducían, principalmente, a la inaplicabilidad de la Ley 1/1995, de Protección Ambiental de la Región de Murcia, en virtud de su Disposición Transitoria $6^{\mathrm{a}}$. Dicha Disposición excluye la aplicación de la Ley regional, en lo relativo a los procedimientos de autorización ambiental, a las actividades o actuaciones que iniciaran los trámites de su aprobación o autorización antes de su entrada en vigor. Sin embargo, el fallo de instancia acertadamente rechaza este argumento y exige la evaluación de impacto ambiental, en primer lugar, porque la Disposición Transitoria se refiere a los procedimientos de «autorización ambiental», mientras que el caso de autos consiste en un procedimiento de aprobación

\footnotetext{
${ }^{15}$ Este inciso fue introducido por la Ley estatal 4/1989, de Conservación de Espacios Naturales Protegidos, de la Flora y la Fauna.

${ }^{16}$ Cfr. artículo 1.2 del Real Decreto Legislativo 1302/1986 de 28 de junio, de Evaluación de Impacto Ambiental. Ahora bien, la obligación relativa de efectuar la evaluación de impacto ambiental, cuando así lo decida el órgano ambiental en cada caso, no será de aplicación en aquellos proyectos para los que la normativa de las Comunidades Autónomas, en el ámbito de sus competencias, bien exija evaluación de impacto ambiental en todo caso, bien haya fijado umbrales para determinar cuándo dichos proyectos deben ser sometidos a dicha evaluación.
} 
de planeamiento; y, en segundo término, porque la modificación del planeamiento afecta a una superficie superior a la legalmente establecida, además de perturbar el estado del Saladar de Lo Poyo ${ }^{17}$.

\section{LA SENTENCIA DEL TRIBUNAL SUPREMO DE 30 DE OCTUBRE DE 2003. LA INELUDIBLE EXIGENCIA DE LA PREVIA EVALUACIÓN DE IMPACTO AMBIENTAL}

La Sentencia de la Sala de lo Contencioso del Tribunal Supremo de 30 de octubre de 2003 (ponente Sr. Yagüe Gil) resuelve el recurso de casación número 7460/2000, interpuesto por la mercantil «Inmobiliaria Altonia, $S L »$, contra la Sentencia del Tribunal Superior de Justicia de Murcia, de 29 de septiembre de 2000, comentada anteriormente.

Los motivos de impugnación que la parte recurrente aduce, paralelamente a las razones en que la Sala de instancia fundó la estimación del recurso, son los dos siguientes: en primer lugar, la improcedencia de un nuevo trámite de información pública, al no tratarse de una modificación sustancial del planeamiento, de acuerdo con los artículos 49.1 del Texto Refundido de la Ley del Suelo de 9 de abril de 1976, 154.1 y 161.1 del Reglamento de Planeamiento. Y, en segundo término, la innecesariedad de la previa evaluación de impacto ambiental, de conformidad con la Disposición Adicional $2^{\mathrm{a}}$ y el artículo 24 de la Ley 4/1989, de Conservación de Espacios Naturales y de la Flora y la Fauna Silvestres, y del artículo 20 de la Ley murciana 1/1995, de Protección del Medio Ambiente.

El Tribunal Supremo, por motivos de lógica jurídica, invierte el orden de estudio de los motivos esgrimidos, en la medida en que el problema de necesidad de evaluación de impacto ambiental es anterior y previo al de la existencia o no de modificaciones sustanciales en la aprobación definitiva del planeamiento. En efecto, si la evaluación de impacto ambiental previa fuera necesaria, el procedimiento no habría podido llegar a fase de aprobación alguna ${ }^{18}$.

De las normas estatales y autonómicas invocadas por la Sala de instancia para justificar la necesidad de la previa evaluación de impacto ambien-

\footnotetext{
${ }^{17}$ Fundamento Jurídico Segundo, 2, in fine, de la STSJ de Murcia.

18 Fundamento de Derecho Cuarto de la STS de 30 de octubre de 2003 (RJ 2003\262232).
} 
tal el Tribunal Supremo se centra en lo establecido en la Disposición Adicional Segunda de la Ley estatal 4/1989, de Conservación de Espacios Naturales y de la Flora y la Fauna Silvestres. A tenor de tal disposición, como ya hemos tenido ocasión de exponer, se considera una actividad sometida a la previa evaluación de impacto ambiental la transformación de uso del suelo que implique eliminación de la cubierta vegetal arbustiva o arbórea y supongan riesgo potencial para las infraestructuras de interés general de la Nación, y, en todo caso, cuando dichas transformaciones afecten a superficies superiores a 100 hectáreas. La parte recurrente en casación afirma que dicha Disposición no es aplicable a la aprobación de planes o sus modificaciones, ya que tales aprobaciones no conllevan por sí mismas transformaciones de uso del suelo. Sin embargo, no discute ni se refiere en su alegación a la concurrencia del requisito de la «eliminación de la cubierta vegetal arbustiva o arbórea», por lo que el Tribunal Supremo da por supuesto que en el presente caso existe dicha eliminación.

Todo lo anterior lleva al Tribunal Supremo a centrarse en la determinación de si la Disposición Adicional 2a de la Ley estatal 4/1989 resulta o no aplicable a la aprobación de Planes que impliquen transformación del uso del suelo ${ }^{19}$. En el presente caso, la modificación del Plan cambia la clasificación del suelo, que de urbanizable no programado pasa a urbanizable programado, lo que posibilita la construcción de 4.400 hectáreas y 3.000 plazas hoteleras, según datos no discutidos por las partes ${ }^{20}$. Con buen criterio, el Tribunal Supremo entiende que «es la aprobación del Plan la que hace posible el cambio de uso del suelo y, por ello, es en ese momento donde se ha de evaluar el impacto ambiental; no sería lógico posponer ese estudio a otro momento posterior (como) la aprobación de Programas de Actuación, o del Plan Parcial, o del Proyecto de Urbanización (...). La primera actuación administrativa que cambia el uso del suelo es el Plan General y él es quien modifica drásticamente su régimen jurídico. En consecuencia, incluso antes de la aprobación inicial, tan pronto como estén claras las líneas generales del avance o proyecto del Plan, el mismo debe

\footnotetext{
${ }^{19}$ Fundamento de Derecho Quinto de la STS de 30 de octubre de 2003.

${ }^{20}$ Es necesario poner de relieve, en este punto, el equívoco en que incurre la Sentencia del Tribunal Supremo al referirse a la alteración de la clasificación del suelo objeto del recurso. En efecto, la mutación llevada a cabo por la Consejería de Política Territorial y Obras Públicas de la Región de Murcia en el supuesto de hecho consiste en convertir el suelo urbanizable programado en urbanizable no programado (vid. Apartado Primero de la Orden de la Consejería de Política Territorial y Obras Públicas, de 30 de julio de 1996 y Fundamento de Derecho Segundo 1 de la Sentencia del Tribunal Superior de Justicia). Sin embargo, la Sentencia del Tribunal Supremo indica en el Fundamento de Derecho Quinto que «(...) en el presente caso, la modificación del Plan cambia la clasificación del suelo, que pasa a ser de no urbanizable a urbanizable — no programado-, y ello constituye sin duda una transformación de su uso (...)».
} 
someterse a una evaluación de impacto ambiental, pues sólo así la Administración planificadora (en la aprobación inicial) y los ciudadanos en general (en la información pública) podrán tener la suficiente ilustración sobre las consecuencias de las transformaciones anunciadas en el medio ambiente» ${ }^{21}$.

En fin, la Sentencia del Tribunal Supremo considera acertada la de la Sala de instancia al aplicar la Disposición Adicional 2a de la Ley 4/1989, pues se trata de una transformación de uso del suelo que implica la eliminación de cubierta vegetal arbustiva. Por ello, el citado Tribunal entiende que carece de sentido adentrarse en el estudio del motivo de casación primero, referente a la existencia o no de modificaciones sustanciales en la aprobación definitiva del Plan General de Ordenación Urbana que hubieran podido exigir una nueva información pública. Y es que, «declarada por la Sala de instancia y por este Tribunal la necesidad de evaluación de impacto ambiental, el proyecto de modificación del Plan ni siquiera debió llegar al umbral de la aprobación inicial» 22 .

\section{EL PRINCIPIO DE AUTONOMÍA LOCAL COMO LÍMITE DEL CONTROL AUTONÓMICO EN LA APROBACIÓN DEL PLANEAMIENTO URBANÍSTICO}

\section{Improcedente aprobación definitiva del planeamiento por parte de la Comunidad Autónoma de la Región de Murcia. Necesidad de un nuevo pronunciamiento municipal}

El principio de autonomía local ha sido definido como «el derecho y la capacidad efectiva de las entidades locales de ordenar y gestionar una parte importante de los asuntos públicos, en el marco de la ley, bajo su propia responsabilidad y en beneficio de sus habitantes» ${ }^{23}$. Qué duda cabe que el urbanismo constituye uno de esos «asuntos públicos» locales sobre los que el Ayuntamiento ha de tener dicha capacidad de actuación. A mayor abundamiento, la mencionada materia representa uno de los ámbitos más genuinos de la comunidad local, hasta el punto que se ha llegado a calificar

\footnotetext{
${ }^{21}$ Fundamento de Derecho Quinto de la STS de 30 de octubre de 2003.

${ }^{22}$ STS últimamente citada, Fundamento de Derecho Séptimo.

${ }^{23}$ Artículo 3.1 de la Carta Europea de Autonomía Local de 15 de octubre de 1985.

${ }^{24}$ En este sentido, véase la STS de 13 de noviembre de 1989, Fundamento de Derecho Segundo (RJ 198918184).
} 
por la jurisprudencia como una competencia «natural» del municipio ${ }^{24}$, pues «no es necesario argumentar particularmente que, entre los asuntos de interés de los Municipios y a los que por tanto se extienden sus competencias, está el urbanismo» ${ }^{25}$.

Ciertamente, concierne a los municipios ordenar y gestionar el mantenimiento, la rehabilitación y el desarrollo de la ciudad; es decir, no sólo actuar sobre aquellos elementos de la misma que han de ser mantenidos, recuperados o rehabilitados, en su caso, por ser representativos de aquella sino también prever, dirigir y controlar su futuro desarrollo ${ }^{26}$. En este sentido, el plan, en tanto concepto central del Derecho urbanístico y manifestación esencial del mismo, prefigura y anticipa lo que al cabo del tiempo será la ciudad o el concreto espacio territorial por él considerado. Pese a todo, desde la Ley sobre régimen del suelo y ordenación urbana de 12 de mayo de 1956, el urbanismo - que hasta entonces era una competencia esencialmente municipal - ha sido una competencia centralizada en los poderes públicos estatales, primero, $\mathrm{y}$, autonómicos después, tras la Constitución de 1978 y los Estatutos de Autonomía de las Comunidades Autónomas, en virtud de los que éstas gozan de competencia exclusiva en materia de ordenación del territorio, urbanismo y vivienda.

Ahora bien, la Carta Magna también garantiza la autonomía de los municipios para la gestión de sus intereses, lo que refuerza, sin duda, la posición de aquellos en el sistema. Este refuerzo se intensifica como consecuencia del denominado «pacto local» que, en lo que ahora interesa, introdujo una importante modificación en el régimen de las aprobaciones municipales de planeamiento. En este sentido, se atribuyen al Pleno las aprobaciones iniciales y provisionales del planeamiento general; sin embargo, la aprobación definitiva, como se sabe, corresponde a la Administración de tutela. Lo que a nosotros nos importa, dado el supuesto de hecho de las sentencias comentadas, es precisar qué alcance tiene la intervención de dicha Administración así como la amplitud con que puede desplegar sus potestades.

El Tribunal Supremo se ha pronunciado con meridiana claridad sobre el ámbito y alcance del trámite de aprobación definitiva en numerosas sentencias, de entre las que es necesario destacar la de 13 de julio de 1990, que efectúa una interpretación acorde con la Constitución de 1978 del ar-

\footnotetext{
${ }^{25}$ STC 40/1998, de 19 de febrero, Fundamento de Derecho 39.

${ }^{26}$ López Pellicer, J. A., Autonomía territorial y competencias municipales. El pacto local en la Región de Murcia, Cuadernos del Consejo Jurídico de la Región de Murcia, núm. 2, Murcia, 2003, p. 88 y 89 .
} 
tículo 41 del Texto Refundido de la Ley del Suelo de 1976. Este precepto establece que el órgano competente para otorgar la aprobación definitiva ha de examinar el proyecto de plan «en todos sus aspectos», lo que se interpretó, con anterioridad al Texto Constitucional, en sentido amplio, como reconocimiento de una potestad de fiscalización comprensiva tanto de aspectos de legalidad como de mera oportunidad o conveniencia. Sin embargo, en buena lógica jurídica, la sentencia expone que este criterio preconstitucional ha de ser entendido a la luz de las exigencias de la autonomía municipal, tal como se deriva del principio de interpretación conforme a la Constitución de todo el ordenamiento jurídico, que opera con especial intensidad respecto de las normas anteriores a la Constitución ${ }^{27}$. Continúa afirmando la sentencia que la Comunidad Autónoma tiene un «control pleno» sobre los aspectos reglados del plan y, en cuanto a los discrecionales, serán sólo viables los controles tendentes a evitar la vulneración de las exigencias del principio de interdicción de la arbitrariedad de los poderes públicos. No serán, en cambio, admisibles revisiones de pura oportunidad, ya que en este terreno ha de prevalecer el modelo físico que dibuja el municipio con la legitimación democrática de que le dota la participación ciudadana que se produce en el curso del procedimiento. Ahora bien, respecto de las determinaciones del planeamiento que tengan conexión con algún aspecto de un modelo territorial superior, además de los controles tendentes a evitar transgresiones del principio de interdicción de la arbitrariedad, resulta también admisible un control de oportunidad en el que prevalece la apreciación comunitaria, en la medida en que en la relación entre el interés local y el supralocal es claramente predominante este último ${ }^{28}$.

En similares términos se vuelve a pronunciar el Tribunal Supremo en la sentencia de 18 de mayo de 1992, en la que mayormente se centra en la afectación de intereses autonómicos. En este sentido manifiesta que el control que efectúa la Administración autonómica de los aspectos discrecionales del plan - como puede ser la clasificación de un suelo de urbanizable o no urbanizable que, de forma expresa, considera «eminentemente discrecional»- exige constatar si las determinaciones inciden o no en materias de interés comunitario. En caso negativo, es decir, si las determinaciones no inciden en materias de interés autonómico, puesto que el plan configura el entorno físico de una convivencia puramente local y sin trascendencia para intereses superiores, tales determinaciones son normas estrictamente municipales, por lo que sólo serán admisibles los controles

\footnotetext{
${ }^{27}$ STS de 13 de julio de 1990, Fundamento de Derecho Tercero (RJ 199016034).

${ }^{28}$ STS de 13 de julio de 1990, Fundamento de Derecho Cuarto (RJ 199016034).
} 
tendentes a evitar la vulneración de las exigencias del principio de interdicción de la arbitrariedad de los poderes públicos. En cuanto a la inadmisibilidad del control de oportunidad y a la prevalencia del modelo físico municipal, el Tribunal Supremo vuelve a pronunciarse en los mismos términos de la sentencia del Tribunal Supremo, de 13 de julio de 1990, expuestos anteriormente ${ }^{29}$.

En consecuencia, las determinaciones de los planes de alcance estrictamente municipal no podrán ser objetadas por la Administración de tutela, en la medida en que constituyen una manifestación de la autonomía de la Corporación, salvo que se deban a razones de estricta legalidad. En este marco, las autoridades urbanísticas superiores podrán aprobar pura y simplemente los planes, denegar su aprobación cuando incurran en vicios de legalidad o sus determinaciones resulten arbitrarias o entren en contradicción con intereses municipales debidamente constatados, o bien dejar en suspenso su aprobación a fin de que se subsanen las deficiencias observadas, elevando posteriormente el texto ya subsanado para su nuevo examen, y pudiendo prescindirse de éste si las modificaciones son de escasa importancia $^{30}$.

Parece claro que, al menos para la jurisprudencia, el principio de autonomía local es compatible con la existencia de controles de legalidad, bien entendido que no se ajusta al mismo la previsión de controles genéricos e indeterminados que sitúen a las Entidades locales en una posición de subordinación o dependencia cuasijerárquica de las demás Administraciones territoriales. En todo caso, los controles de carácter puntual habrán de referirse normalmente a supuestos en que el ejercicio de las competencias de la Entidad local incidan en intereses generales concurrentes con los propios de la Entidad. En suma, la autonomía garantizada por la Constitución quedaría afectada en los supuestos en que la decisión correspondiente a la «gestión de los intereses respectivos» fuera objeto de un control de oportunidad de forma tal que la toma de la decisión viniera a compartirse por otra Administración ${ }^{31}$.

Consecuentemente con lo expuesto anteriormente, y en lo que se refiere ya al supuesto de hecho de la sentencia de instancia, la Administración autonómica debió respetar el modelo presentado por la Administración

\footnotetext{
${ }^{29}$ STS de 18 de mayo de 1992, Fundamento de Derecho Tercero (RJ 1992\4219).

${ }^{30}$ Fernández Rodríguez, T. R., Manual de derecho urbanístico, El Consultor de los Ayuntamientos y de los Juzgados, Madrid, 2004, $17^{\text {a }}$ edición, p. 95.

${ }^{31}$ STC 4/1981, de 2 de febrero (Pleno), Fundamento Jurídico 3.
} 
actuante, sin alterar la clasificación local del suelo, en la medida en que no es ésta una cuestión que trascienda los intereses municipales. En todo caso, resulta claro que, en rigor, la Comunidad Autónoma debería haber suspendido la aprobación definitiva de la modificación del planeamiento, para someter las deficiencias observadas a la subsanación por parte de la Entidad local. Con la devolución a ésta del expediente para la emisión de un nuevo pronunciamiento municipal que hubiera materializado el cambio de la clasificación del suelo, tal y como impone el artículo 132.3 b) del Reglamento de Planeamiento, se habría evitado que la voluntad autonómica suplantara definitivamente a la local ${ }^{32}$. De este modo, como acertadamente pone de manifiesto el Tribunal Superior de Justicia de Murcia en la sentencia de instancia, es de todo punto necesario un nuevo pronunciamiento municipal en el que se efectúe la nueva clasificación del suelo ${ }^{33}$.

\section{Necesaria reinterpretación del concepto de «interés local» para completar el principio de autonomía local}

\subsection{Exigencia de reconocer al Municipio la facultad de aprobar definitivamente el planeamiento general para alcanzar la plenitud del principio de autonomía local en materia urbanistica}

Constituye una prístina reivindicación de un importante sector doctrinal, no del todo abrazada por el legislador autonómico ni por la jurisprudencia en general, la necesidad de que - colmando los requerimientos de la autonomía local— se aborde decididamente una vertebración del Esta-

\footnotetext{
${ }^{32}$ El artículo 132.3 del Reglamento de Planeamiento, aprobado por Decreto 2159/1978, de 23 de junio, dispone que «cuando el expediente esté formalmente completo, la Administración competente podrá adoptar alguna de estas decisiones: b) suspender la aprobación del Plan por deficiencias que debe subsanar la Entidad u Organismo que hubiere otorgado la aprobación provisional, devolviendo a ésta el expediente».

${ }^{33}$ El Tribunal Supremo se ha manifestado en estos términos en su sentencia de 26 de diciembre de 1991 (RJ 19921376) al disponer, en los Fundamentos de Derecho Segundo y Tercero, que en los supuestos de introducción de modificaciones esenciales el órgano encargado de la aprobación definitiva no puede otorgarla, si antes no suspende el procedimiento para abrir un nuevo trámite de información pública y conceder audiencia a las Corporaciones Locales interesadas. Por ello, lo procedente por imperativo legal es decretar la suspensión con devolución del expediente para continuar los trámites legalmente establecidos ante el Ayuntamiento actor como competente para dictar la aprobación provisional.

${ }^{34}$ Ciertamente, esta reivindicación ya fue formulada hace quince años por MeILÁn Gıl, J. L., en «Autonomías y descentralización local», Revista de Estudios de la Administración Local y Autonómica, núm. 243, Madrid, 1989, p. 545 y siguientes.
} 
do a segundo nivel ${ }^{34}$. Esta exigencia es consecuencia natural de la atención preferente que desde sus orígenes se ha prestado a la estructura fundamental del Estado compuesto, esto es, a la relación existente entre el Estado y las Comunidades Autónomas, conocida como la vertebración del Estado a primer nivel. El estadio alcanzado actualmente en el binomio Estado-Comunidades Autónomas exige avanzar un nivel más, haciendo realidad la vertebración intracomunitaria, cuya imposición indefectible proviene de la relación «natural» existente entre éstas y las Corporaciones Locales ${ }^{35}$. Es tiempo, pues, de que cada Comunidad Autónoma diseñe un modelo de Pacto Local para su ámbito territorial.

Ciertamente, el reclamo más acusado de la autonomía local se ha producido en el ámbito urbanístico, respecto del que se considera que la necesidad de establecer una adecuada distribución de competencias entre la Comunidad Autónoma y los municipios obedece no sólo a la necesidad de garantizar la autonomía local constitucionalmente reconocida, sino también a la exigencia de servir con eficacia el interés general de los ciudadanos que, en este ámbito de actuación, tiene un marcado carácter social ${ }^{36}$.

Esta corriente doctrinal propugna la necesidad de abandonar el modelo de control centralizado en la aprobación del planeamiento urbanístico general a favor de la competencia municipal, es decir, la superación del procedimiento bifásico existente en este ámbito. No se trata de impedir que la Comunidad Autónoma preserve la legalidad en relación con lo que excede de la competencia municipal al incidir en intereses supralocales, sino de que se utilicen las técnicas jurídicas, sin atentar a la naturaleza de las instituciones a que deben servir, en los términos que vamos a ver seguidamente. La adopción de tal postura supondría considerar la aprobación definitiva del planeamiento urbanístico general como una potestad municipal, todo ello a la luz de la Constitución, los Estatutos de Autonomía y, cómo no, de la Ley 7/1985, de Régimen Local, que, al suponer la concreción de los artículos 137, 140 y 141 de la Constitución forma parte, en determinados contenidos, del llamado «bloque de la constitucionalidad». Debemos situar este reclamo en el entendimiento de que «ya es hora de reconocer la autonomía local en una materia sobre la que (los municipios) tienen también reconocida competencia, según el artículo 25.2.d) de la Ley de Bases del Régimen Local» ${ }^{37}$. Esta operación debe efectuarse a

\footnotetext{
${ }^{35}$ STC 331/1993, de 12 de noviembre, Fundamento Jurídico 2.

${ }^{36}$ Meilán GIL, J. L., «Autonomía y planeamiento urbanístico», Revista de Estudios de la Administración Local, núm. 288, 2002, p. 40.
}

${ }^{37}$ MeILÁn GIL, J. L., «Autonomía y planeamiento...», ob. cit., pp. 50-51. 
LA AUTONOMÍA LOCAL EN EL TRÁMITE DE APROBACIÓN DEL PLANEAMIENTO URBANÍSTICO GENERAL

la luz del bloque de la constitucionalidad en la medida en que no se plantea conflicto alguno con la Carta Magna. Tan sólo ha de efectuarse una interpretación más amplia de lo que debe entenderse por «intereses locales», avanzando en la fijación de los mismos y adoptando una posición más decidida a la hora de garantizar ámbitos competenciales concretos ${ }^{38}$.

Desde la postura expuesta no se entiende la causa de que la aprobación definitiva del planeamiento general así como sus modificaciones no sea exclusivamente municipal más allá de ser consecuencia de un inmoderado sentido expansivo de la competencia así como una inercia que deriva de postulados legales diferentes a los actuales, que revela una cierta tutela administrativa incompatible con la autonomía ${ }^{39}$. En este sentido, la intervención autonómica en la aprobación definitiva se presenta como un acto de fiscalización o control, manifestación de la tutela propia de un Estado unitario centralista en su más clásica formulación, que «implica la consideración jurídica de los actos tutelados como menores de edad. Es decir, su voluntad no vale o no es eficaz si no se le une otra voluntad plenamente capaz, la del tutor» ${ }^{40}$.

\subsection{Fórmulas que garantizan la ineludible protección de los intereses supralocales}

El principal óbice que ha de sortear la reivindicación expuesta a favor de la autonomía local en el campo urbanístico consiste en la necesidad de salvaguardar los intereses supralocales — no sólo autonómicos sino también estatales- que puedan verse afectados. Y es que, como bien sabemos, la autonomía hace referencia a un poder limitado, en la medida en que autonomía no es soberanía y, dado que cada organización territorial dotada de autonomía es una parte del todo, en ningún caso el principio de

\footnotetext{
${ }^{38}$ Para Vallina Velarde tanto en la LBRL, con la función constitucional que le es propia, como en la Carta Europea de Autonomía Local existe base suficiente para realizar la mencionada labor de interpretación extensiva de los intereses locales. (De la Vallina Velarde, J.L., «Autonomía local y aprobación por delegación de los planes generales de urbanismo», Revista de Estudios de la Administración Local, núm. 288, 2002, p. 21-22).

${ }^{39}$ F. Perales Madueño, «La gestión en la legislación urbanística», La carestía del suelo, La Ley, Madrid, 2000, p. 241 y MeILÁN GIL, J.L., «Autonomía y planeamiento...», ob. cit., p. 50. También De la vallina Velarde, J.L., «Autonomía local y aprobación por delegación...», ob. cit., p. 17 y LóPez Pellicer, J. A., «La autonomía municipal en el trámite de elaboración y aprobación del planeamiento urbanístico general», Revista urbanística práctica, núm. 6, La Ley, 2002, p. 43.

40 Morell Ocaña, L., El Régimen local español, Civitas, Madrid, 1988, p. 85. En igual sentido, De la vallina Velarde, J.L., «Autonomía local y aprobación por delegación...», ob. cit., p. 14 y LÓPEz Pellicer, J.A., «La autonomía municipal en el trámite...», ob. cit., p. 46.
} 
autonomía puede oponerse al de unidad, ya que es precisamente dentro de éste donde alcanza su verdadero sentido ${ }^{41}$. En este sentido, si positivamente la autonomía municipal significa un derecho de la comunidad local a la participación, a través de órganos propios, en el gobierno y administración de los asuntos que le atañen, negativamente no se garantiza, sin embargo, por la Constitución para incidir de forma nociva sobre los intereses generales de la nación, [de la Comunidad Autónoma], o en otros intereses de la entidad local ${ }^{42}$.

Consecuentemente con lo anterior y, a mayor abundamiento, la jurisprudencia concibe la de urbanismo como una competencia material de titularidad compartida por los municipios y las comunidades autónomas — dada la diversidad de intereses presentes en el mismo- que se articula en un procedimiento bifásico en el que las aprobaciones iniciales, provisional y definitiva se distribuyen entre aquellas en función de la supremacía del interés supralocal. Precisamente por ello, para el Tribunal Supremo está justificado que, en el aspecto temporal, la decisión autonómica se produzca con posterioridad a la municipal y que, en el sustantivo, aquella haya de contemplar el plan no sólo en sus aspectos reglados sino también en los discrecionales que, por su conexión con intereses supralocales, hayan de ser valorados para asegurar una coherencia presidida por la prevalencia de tales intereses superiores ${ }^{43}$.

Sin embargo, la preservación de los intereses supralocales en juego no exige el mantenimiento de la fórmula tradicional de la aprobación definitiva del planeamiento general, en la medida en que existen otras posibilidades igualmente lícitas y más respetuosas con el principio de autonomía local. Veámoslas por separado.

\subsubsection{El carácter condicionado de los planes urbanísticos}

El carácter de auténticas normas jurídicas que tienen los planes urbanísticos - en concreto, de normas reglamentarias - conlleva, en primer término, que aquellos hayan de respetar las determinaciones de las leyes urbanísticas de las que traen causa, tanto estatales como autonómicas. En segundo término, supone que han de respetar también los instrumentos de ordenación del territorio así como las políticas territoriales que tengan incidencia en el

\footnotetext{
${ }^{41}$ STC 4/1981, de 2 de febrero, Fundamento Jurídico 3.

${ }^{42}$ STS de 13 de julio de 1990, Fundamento de Derecho Tercero (RJ 1990\6034).

${ }^{43}$ Cfr. última Sentencia del Tribunal Supremo citada, Fundamento de Derecho Tercero.
} 
término municipal, pues es en la planificación territorial donde se constatarán los elementos que representan el interés supralocal —autonómico(vías de comunicación, infraestructuras, etc.). La salvaguarda de estos intereses derivada del fuerte condicionamiento de los planes urbanísticos hace que no parezca imprescindible someterlos al control puntual que supone la aprobación por parte de la Comunidad Autónoma de cada plan general ${ }^{44}$.

\subsubsection{Emisión de informes preceptivos y, en su caso, vinculantes por parte de la Administración titular del interés afectado}

Es éste un sistema por el que ya ha optado la legislación estatal para garantizar la competencia de la Administración General del Estado frente a otras Administraciones públicas y que, sin duda, podría trasladarse a las leyes autonómicas correspondientes ${ }^{45}$. Podría, de este modo, exigirse a la Comunidad Autónoma correspondiente la emisión de un informe preceptivo y vinculante antes de la aprobación definitiva del plan general por el Ayuntamiento. Al citado informe, que habrá de ser motivado, deberá dársele la correspondiente publicidad y servirá tanto para su ponderación por el Ayuntamiento, como para la fundamentación jurídica en la eventual impugnación por la Comunidad Autónoma del plan ${ }^{46}$.

\subsubsection{La coordinación como técnica rectora de las relaciones interadministrativas}

De sobra es sabido que en un Estado compuesto como el español las relaciones interadministrativas cobran vital importancia, así como que

\footnotetext{
${ }^{44}$ En este sentido, De la vallina Velarde, J.L., «Autonomía local y aprobación por delegación...», ob. cit., p. 31 y MeILÁN GiL, J.L., «Autonomía y planeamiento...», ob. cit., p. 53.

${ }^{45}$ Qué duda cabe que los intereses propios del Estado en materias tan importantes como la defensa nacional, costas, aguas continentales, carreteras, etc., pueden verse afectados, y, sin embargo, por este motivo no se le atribuye la aprobación definitiva del planeamiento general. Antes bien, aquéllos se consideran suficientemente protegidos mediante la emisión del correspondiente informe vinculante y la legitimación para impugnar la disposición del plan que los vulnere. Cfr. en este sentido, la Disposición Adicional $1^{\text {a }}$ de la Ley 6/1998, de 13 de abril, de Régimen del Suelo y Valoraciones; el artículo 19 de la Ley 16/2002, de 1 de julio, de Prevención y Control Integrados de la Contaminación; el artículo 10 de la Ley 26/1988, de 29 de julio, de Carreteras; los artículos 112 y 116, de la Ley 22/1988, de 28 de julio, de Costas; el artículo 18 de la Ley 27/1992, de Puertos del Estado y de la Marina Mercante, y el artículo 128 del Texto Refundido de la Ley de Aguas, aprobado por Real Decreto Legislativo 1/2001, de 20 de julio.

${ }^{46}$ En este sentido, MeILÁn Gil, J.L., «Autonomía y planeamiento...», ob. cit., p. 51, De LA VALLINA Velarde, J.L., «Autonomía local y aprobación por delegación...», ob. cit., p. 29, LóPez Pellicer, J.L., «La autonomía municipal en el trámite...», ob. cit., p. 45 y siguientes.
} 
aquellas que tengan lugar entre la Administración del Estado o la de las Comunidades Autónomas con las Entidades Locales se rigen, de forma prioritaria, por la Ley de Bases del Régimen Local ${ }^{47}$. Y, como no podía ser de otro modo, el Capítulo II del Título V de la citada Ley — que regula las citadas relaciones interadministrativas - erige al principio de coordinación en uno de los pilares que cimientan las mismas ${ }^{48}$. En este sentido y con carácter general, el artículo 10 de LBRL obliga a la Administración Local y a las demás Administraciones públicas a ajustar sus relaciones recíprocas a los deberes de información mutua, colaboración, coordinación y respeto a los ámbitos competenciales respectivos. Procediendo, además, la coordinación de las competencias de las entidades locales con las restantes Administraciones públicas cuando las actividades o los servicios locales trasciendan el interés propio de las correspondientes Entidades, incidan o condicionen relativamente los de dichas Administraciones o sean concurrentes o complementarios de los de éstas.

A mayor abundamiento, para la efectividad de la coordinación y la eficacia administrativas, las Administraciones públicas, en sus relaciones recíprocas, deberán prestar la cooperación y asistencia activas que las otras Administraciones puedan precisar para el eficaz cumplimiento de sus tareas. Además, las Entidades locales ejercerán sus facultades de programación, planificación u ordenación de los servicios o actividades de su competencia en el marco de las previsiones de los planes sectoriales estatales y autonómicos ${ }^{49}$.

\subsubsection{El control jurisdiccional del planeamiento urbanístico general}

Como venimos poniendo de manifiesto, el reconocimiento a las Entidades locales de la potestad de aprobar definitivamente el planeamiento general no ha de estar reñido con el control de legalidad del planeamiento general que afecte a intereses autonómicos o estatales. Lo que no debe admitirse ya es que dicho control sea administrativo, es decir, que el con-

\footnotetext{
${ }^{47}$ Vid. artículo 9 de la Ley 30/1992, de 26 de noviembre, de Régimen Jurídico de las Administraciones Públicas y del Procedimiento Administrativo Común.

${ }^{48}$ Huelga decir que la coordinación a la que nos referimos es la coordinación intersubjetiva, no jerárquica o externa, que es aquella que tiene lugar entre órganos integrados en distintas instancias, entre las que no media relación de jerarquía, ni aún de subordinación orgánica de cualquier otra especie y cuyo fundamento es conseguir la coherencia, armonía y conjunción en la elaboración y ejecución de la decisión administrativa. Un estudio de la coordinación y demás principios organizativos que cimientan el sistema estatal descentralizado puede en MarTínez Marín, A., Una teoría sobre nuestra organización pública y sus principios, Tecnos, Madrid, 1996, pp. 125 y siguientes.

${ }^{49}$ Cfr. artículos 55 y 59.1 in fine de la LBRL.
} 
trol de los aspectos de legalidad ha de ser en el ordenamiento actual y en virtud del principio-derecho de autonomía local un control jurisdiccional y no de tutela administrativa. Dicho control jurisdiccional debe realizarse conforme a los artículos 65 ó 66 de la LBRL que permiten al Estado y a las Comunidades Autónomas, en el ámbito de sus respectivas competencias, la impugnación de los actos de las Administraciones locales que infrinjan el Ordenamiento jurídico, menoscaben sus competencias, interfieran su ejercicio o excedan de las competencias de dichas Entidades. Este régimen presupone la competencia municipal para adoptar los acuerdos correspondientes en materias locales, incluso el de aprobación definitiva, sin perjuicio, claro está, de la posible impugnación jurisdiccional por parte de las Administraciones supralocales, de conformidad con la Ley de la Jurisdicción Contencioso-Administrativa ${ }^{50}$.

\section{CONCLUSIÓN}

Como ha quedado expuesto, la exigencia de la previa evaluación de impacto ambiental no constituye una cuestión controvertida ni para la sentencia de instancia ni para la de casación. La Orden de la Consejería de Política Territorial y Obras Públicas de la Comunidad Autónoma de la Región de Murcia de 30 de julio de 1996 aprueba una modificación del Plan General de Ordenación Urbana de Cartagena que implica la eliminación de cubierta vegetal arbustiva o arbórea en 469 hectáreas, lo que supera, en mucho, el límite de 100 hectáreas establecido en la Disposición Adicional $2^{a}$ de la Ley 4/1989, de Conservación de Espacios Naturales y de la Flora y la Fauna Silvestres. Esta sola circunstancia es, a juicio del Tribunal Supremo, motivo suficiente para exigir la previa evaluación de impacto ambiental. Para la sentencia de instancia, además, tal exigencia deriva del anexo I de la Ley 1/1995, de Protección del Medio Ambiente de la Región de Murcia en cuya virtud han de someterse a la previa evaluación de impacto ambiental las modificaciones y revisiones de los Planes Generales de Ordenación Urbana que reduzcan la superficie de suelo urbanizable. Consecuentemente el Tribunal Supremo confirma la sentencia de instancia estimatoria del recurso contencioso-administrativo.

Ahora bien, el Tribunal Supremo no se adentra en el estudio de los demás motivos de casación referentes a la existencia o no de modificaciones sustanciales en la aprobación definitiva del planeamiento que hubieran podido exigir nueva información pública y, por ende, de la suplantación de

\footnotetext{
${ }^{50}$ LóPez Pellicer, J. A., «La autonomía municipal en el trámite...», ob. cit., p. 44.
} 
la voluntad municipal que, en última instancia conlleva, ya que sin la previa evaluación de impacto ambiental el proyecto no debió ni siquiera llegar al umbral de la aprobación inicial. En el trabajo se ha puesto de relieve que la exigencia del nuevo pronunciamiento municipal para llevar a cabo la reclasificación del suelo hubiera evitado la citada suplantación de la voluntad municipal por la autonómica, como efectivamente sucedió en el caso de autos. En estricto cumplimiento de la legalidad vigente, la Orden de la Consejería debió suspender la aprobación definitiva de la modificación del planeamiento, remitiendo el expediente al Ayuntamiento para que efectuara la reclasificación de los terrenos afectados y subsanara las deficiencias observadas por la Comunidad Autónoma.

A propósito del comentario de este último extremo, es decir, de la competencia de la Comunidad Autónoma para aprobar definitivamente el planeamiento urbanístico general, y posicionándonos con la postura doctrinal que lo propugna, se ha vuelto a reivindicar la concentración en instancias locales de la potestad de aprobar definitivamente todo el planeamiento urbanístico, incluido el general. Como se ha indicado, un sector doctrinal viene haciéndose eco de tal demanda ante el entendimiento de que la situación actual de intervención administrativa mediante diversos controles supone la consideración de «menores de edad» de nuestras entidades locales. Hemos llegado, pues, a un nivel de superación de los controles administrativos de ciertas actividades locales, máxime cuando la misma finalidad de control puede lograrse mediante otros instrumentos igualmente lícitos y más respetuosos con la autonomía local. No se encuentra impedimento para atribuir la potestad de aprobación definitiva del planeamiento de sus propias ciudades a los entes locales, sobre todo cuando ya se ha efectuado dicha atribución sobre otras competencias igualmente domésticas pero sobre las que ha existido una mayor tradición interventora, como es la aprobación de los presupuestos municipales (artículo 150 de la Ley 39/1988, reguladora de las Haciendas Locales).

Para concluir, y trascendiendo del plano meramente urbanístico, se hace necesario superar el actual neocentralismo autonómico en el que estamos inmersos desde la división territorial del Estado efectuada por la Constitución de 1978. De igual modo, constituye el mejor instrumento para articular tal superación el llamado «segundo Pacto Local», que ha de efectuarse entre las Comunidades Autónomas y las Corporaciones Locales, con la consabida finalidad de reconocer y atribuir a éstas facultades innecesariamente retenidas por las Administraciones autonómicas, como es la urbanística. 
LA AUTONOMÍA LOCAL EN EL TRÁMITE DE APROBACIÓN DEL PLANEAMIENTO URBANÍSTICO GENERAL

\section{BIBLIOGRAFÍA}

Agudo GonzÁlez, J.: «Evaluación de impacto ambiental: problemas jurídicos»; Revista de Derecho urbanístico y medio ambiente, núm. 176, 2000 .

Alli Aranguren, J. C.: «Dos sentencias sobre las competencias y la naturaleza jurídica de la declaración de impacto ambiental», Actualidad Administrativa, núm. 35, 2001.

ARCE RuIz, R. M.: La evaluación de impacto ambiental en la encrucijada: los retos del futuro, La Ley, Madrid, 2002.

Betancor Rodríguez, A.: Instituciones de Derecho Ambiental, La Ley, Madrid, 2001.

FERnÁNDEZ Rodríguez, T. R.: Manual de derecho urbanístico, $17^{\mathrm{a}}$ edición, El Consultor de los Ayuntamientos y Juzgados, Madrid, 2004.

JiMÉNEZ SÁNCHEZ, G.: «Configuración constitucional y tutela de la autonomía local», Revista Andaluza de Administración Pública, núm. 51, 2003.

López Pellicer, J. A.: Autonomía territorial y competencias municipales. El pacto local en la Región de Murcia, Consejo Jurídico de la Región de Murcia, Cuadernos, Murcia, 2003.

— «La autonomía municipal en el trámite de elaboración y aprobación del planeamiento urbanístico general», Revista Práctica Urbanística, núm. 6, 2002.

Lozano Cutanda, B.: Derecho Ambiental Administrativo, $4^{\mathrm{a}}$ edición, Dykinson, Madrid, 2003.

MarTínez Marín, A., Una teoría sobre nuestra organización pública y sus principios, Tecnos, Madrid, 1996.

Meilán Gil, J. L.: «Autonomías y descentralización local», Revista de Estudios de la Administración Local y Autonómica, núm. 243, Madrid, 1989.

— «Autonomía y planeamiento urbanístico», Revista de Estudios de la Administración Local, núm. 288, Madrid, 2002. 
Oñate, J.J., Pereira, D., Suárez, F., Rodríguez, J.J., y Cachón, J., Evaluación Ambiental Estratégica: la evaluación ambiental de Políticas, Planes y Programas, Mundi-Prensa, Madrid, 2002.

Parejo Alfonso, L.: «La autonomía local en la Constitución», Tratado de Derecho Municipal, obra colectiva dirigida por MuÑoz Machado S., tomo I, $2^{\text {a }}$ edición, Civitas, Madrid, 2003.

Perales Madueño, F.: «La gestión en la legislación urbanística», La carestía del suelo, La Ley, Madrid, 2000.

RazQuin Lizarraga, J. A.: La evaluación de impacto ambiental: estudio jurisprudencial, Aranzadi, Pamplona, 2000.

Santos Diez, R., Castelao Rodríguez, J.: Derecho urbanístico. Manual para juristas y técnicos, $5^{\text {a }}$ edición, El Consultor de los Ayuntamientos y de los Juzgados, Madrid, 2002. 


\section{Crónicas y documentos}

